\title{
Evaluation of Patients for High-risk Obstructive Sleep Apnea from a Dental Perspective: A Cross-sectional Study
}

\author{
Deepa Jatti Patil ${ }^{1}$, Manjiri Joshi
}

\begin{abstract}
Aim and objective: To evaluate patients presenting to a Dental Hospital's healthcare facility for the factors linked with the development of high-risk obstructive sleep apnea (OSA) through oral and radiographic examination.

Materials and methods: A cross-sectional study was performed to identify the patients at high risk of OSA. The patients were screened with the Snoring, Tired, Observed, and Blood Pressure (STOP)—BANG questionnaire, followed by oropharyngeal examination and lateral cephalography. Results:Three hundred patients were screened for the risk of OSA out of which 194 (64.6\%) were men and 106 (35.3\%) were women. One hundred twenty-four (41.3\%) belonged to the high-risk group and 176 (58.6\%) to the low-risk (control) group. Logistic regression analysis confirmed that in the high-risk OSA group, neck circumference, class 3 or 4 Mallampati scores, temporomandibular disorder (TMD), bruxism, wide tongue, and deep palatal vault were all often seen parameters and were independent indications of developing high risk of OSA. The cephalometric analysis revealed decreased airway spaces in the high-risk group with downward displacement of the hyoid bone.

In the high-risk OSA group, neck circumference, class 3 or 4 Mallampati scores, TMD, bruxism, wide tongue, and deep palatal vault were all often seen parameters and were independent indications of developing high risk of OSA.

Conclusion: This study throws light on the imperative role of orofacial features in screening high-risk OSA patients. Dental sleep medicine is an upcoming branch with diversified treatment modalities. Because OSA has been related to the development of fatal medical disorders, it is critical to educate patients about sleep problems and their consequences.

Clinical significance: Oral and radiographic findings can play a pivotal role in identifying patients at risk for OSA. As the general population is unaware about the systemic implications of OSA, the screening for OSA should be conducted as a routine procedure by oral physicians. Oral examination can be a cost-effective tool in screening OSA.
\end{abstract}

Keywords: Cephalometry, Dental sleep medicine, Diagnosis, Obstructive sleep apnea, Oral screening.

World Journal of Dentistry (2022): 10.5005/jp-journals-10015-1898

\section{INTRODUCTION}

Sleep is a key element of our day-to-day life, and we spend approximately one third of our life sleeping. Some of us have a disturbed sleeping pattern due to stress or other factors, but it is usually transient. It is a cause for concern when it happens frequently, suggesting a sleep ailment. ${ }^{1}$ Sleep-related breathing illnesses (SRBDs) are the most frequent type of sleep ailments, with a prevalence between $2 \%$ and $4 \%$. Obstructive sleep apnea (OSA) is the most common type of SRBD. According to a global prevalence estimation of OSA (2019), approximately 1 billion adults world-wide aged between 30 and 69 years with and without symptoms had OSA based on apnea-hypopnea index (AHI). There is a wide geographical variation in the prevalence of OSA and is more than $50 \%$ in some countries. $^{2}$

According to Heinzer et al., the prevalence of OSA is $23.4 \%$ in women and $49.7 \%$ in men. With progressive age, the prevalence of OSA in women is closer to men. ${ }^{3}$ In people with OSA, the upper airway obstruction causes respiratory hypopneas (reductions) or apnea (pauses), despite persisting respiratory efforts that terminate when central nervous system arousal restores airway patency. The immediate effects are oxyhemoglobin desaturation, blood pressure and heart rate fluctuations, sustained sympathetic excitation, cortical arousal, and sleep fragmentation. Long-term effects include neurocognitive impairment, metabolic syndrome, systemic hypertension, and cardiovascular disease. ${ }^{4,5}$

The gold standard for diagnosing OSA is polysomnography (PSG), which records $\mathrm{AHI}$, value $\geq 5$ per hour confirms OSA.
${ }^{1}$ Department of Oral Medicine and Radiology, KM Shah Dental College and Hospital, Sumandeep Vidyapeeth (Deemed to be University), Vadodara, Gujarat, India

${ }^{2}$ Department of Oral Medicine and Radiology, Manubhai Patel Dental College, Hospital and Oral Research Institute, Vadodara, Gujarat, India

Corresponding Author: Deepa Jatti Patil, Department of Oral Medicine and Radiology, KM Shah Dental College and Hospital, Sumandeep Vidyapeeth (Deemed to be University), Vadodara, Gujarat, India, Phone: +91 8847457128, e-mail: id-iafdeepa@gmail.com

How to cite this article: Patil DJ, Joshi M. Evaluation of Patients for High-risk Obstructive Sleep Apnea from a Dental Perspective: A Cross-sectional Study. World J Dent 2022;13(1):26-34.

Source of support: Nil

Conflict of interest: None

Polysomnography is the global standard for diagnosing OSA, which records the $\mathrm{AHI}$, and a value of 5 per hour indicates OSA. This index categorizes the degree of severity of OSA as: 5-15, mild; $15-30$, moderate; and more than 30 , severe. This technique is performed in a sleep lab where the patient is monitored while he sleeps; it records several variables over a period of time. ${ }^{6}$ Patients are frequently unaware of the negative consequences of sleep problems; thus, they refuse to undertake this costly test. ${ }^{7}$ Many questionnaires, such as Snoring, Tired, Observed, and Blood Pressure (STOP), Berlin, Epworth Sleepiness Scale, and STOP-BANG

(c) The Author(s). 2022 Open Access This article is distributed under the terms of the Creative Commons Attribution 4.0 International License (https://creativecommons. org/licenses/by-nc/4.0/), which permits unrestricted use, distribution, and non-commercial reproduction in any medium, provided you give appropriate credit to the original author(s) and the source, provide a link to the Creative Commons license, and indicate if changes were made. The Creative Commons Public Domain Dedication waiver (http://creativecommons.org/publicdomain/zero/1.0/) applies to the data made available in this article, unless otherwise stated. 
questionnaire, have been designed and validated to screen for OSA in patients. ${ }^{8}$ The STOP questionnaire is the most widely used, with a sensitivity of $72 \%$, which rises to $83.6 \%$ when body mass index (BMI), age, neck circumference, and gender are included (STOP-BANG questionnaire). ${ }^{9,10}$

According to a systematic review by Senaratna et al., ${ }^{11}$ increasing age, higher $\mathrm{BMI}$, and male gender are the three major established risk factors for developing OSA. Excessive daytime sleepiness and loud snoring are the alarming clinical indicators for OSA. The predisposing orofacial features are hypertrophied tonsils and uvula, deep palatal vault, macroglossia, increased facial height, and length of the soft palate with decrease in airway spaces. The orofacial features are additional parameters proposed by the American Academy of Sleep Medicine (AASM) for assessing OSA. ${ }^{6,12}$

American Academy of Sleep Medicine has recommended oral appliances for the treatment of OSA making dental sleep medicine an important contributing branch for diagnosis and treatment of OSA. Dental sleep medicine is a new area of dentistry that focuses on diagnosing sleep disorders using orofacial features and treating them with oral appliances. Cephalometric analysis is a useful tool and can be included in the diagnosis - treatment protocol of OSA. The characteristic radiographic features most commonly observed on cephalogram in OSA include short mandible, narrow pharyngeal space, long soft palate, and low positioning of the hyoid. ${ }^{12}$

In Indian studies prevalence of OSA varies from 4.4 to $13.7 \%{ }^{13}$ and a large number of populations remains undiagnosed. Very few studies have been conducted in Indian scenario to assess the risk of OSA based on oral and radiographic examination. ${ }^{14}$ In light of this, the current study was designed to screen patients who presented to the dental outpatient department with the purpose of analyzing the parameters associated with high-risk OSA using a questionnaire, followed by an oral and radiographic examination.

\section{Materials and Methods}

A cross-sectional study was conducted among patients presenting for routine dental treatment to the Department of Oral Medicine and Radiology, after obtaining Institutional Ethical Clearance (IEC/MPDC_152/OD-11/18). The study comprised 300 patients over the age of 18 years, who provided written informed consent and were willing to complete the questionnaire and undergo assessment. Patients younger than 18 years of age, patients with chronic morbidities, and unwilling to participate in the study were excluded from the study. A sample size of 300 was estimated to assess the prevalence of high-risk OSA based on the study by Kale et al. (2018) with a power of $80 \%$.

The study population was then divided into two groups (high risk and low risk) based on the STOP BANG questionnaire as mentioned below. ${ }^{15}$

S-snoring, Do you snore loudly (loud enough to be heard through closed doors or your bed partner elbows you for snoring at night?)

T-tired, Do you often feel tired, fatigued, or sleepy during the daytime (such as falling asleep during daytime, while driving or talking to someone else)

O-observed, Has anyone observed you stop breathing or choking/gasping during your sleep?

P-pressure, Do you have or are being treated for high blood pressure?

B-BMI $>35 \mathrm{~kg} / \mathrm{m}^{2}$ ?

A-age older than 50 years?
$\mathrm{N}$-neck size large more than 17 inches for men and more than 16 inches for womens

$$
\text { G-gender: male? }
$$

- Group I: High risk for OSA (patients responding "YES" to 5 or more questions).

- Group II: Low risk (control group) for OSA (Patients responding "NO" to less than two questions).

- Body mass index was calculated by dividing the weight in kilograms by square of the height in meters according to the metric standards as recommended by WHO. ${ }^{16}$

- Neck circumference was measured along the cricoid cartilage in erect position.

Additional parameters evaluated

- Facial profile (concave, straight or convex) was assessed by imagining a line passing through glabella, subnasale, and the pogonion. ${ }^{17}$

- Temporomandibular disorders (TMD) were classified using the diagnostic criteria (DC)/TMDs criteria. ${ }^{18}$ The TMD examination was performed by trained oral medicine specialists with an experience of more than 10 years. The patients were classified in to myofascial pain, internal disc derangement, or osteoarthritis according to the DC/TMD criteria.

- Bruxism: The presence of bruxism was evaluated by a questionnaire based on the DC of the "AASM" (2005). ${ }^{19}$ The questionnaire refers to events during the past 6 months as follows:

- "Are you aware, or has anyone heard you, grinding your teeth frequently during sleep? (yes/no)

- Are you aware that your dentition is worn down more than it should be? (yes/no)

- Are you aware of any of the following symptoms upon awakening? (yes/no):

- Sensation of fatigue, tightness, or soreness of your jaw upon awakening?

- Feeling that your teeth are clenched or that your mouth is sore upon awakening?

- Aching of your temples upon awakening?

- Difficulty in opening your mouth wide upon awakening?

- Feeling of tension in your jaw joint upon awakening and feeling as if you have to move your lower jaw to release it?

- Hearing or feeling a "click" in your jaw joint upon awakening that disappears afterwards?"

Respondents were scored as suffering from active sleep bruxism if their answer was positive to question 1 and/or question 2, in addition to at least one positive answer to a symptom listed in question 3.

Intraoral soft tissue examination includes assessment of the following:

- Palatal vault shape was noted as deep when the distance between the occlusal surface and the palatal vault appeared increased and the lateral distance appeared constricted, medium when the palatal vault shape was ideal, or shallow when the distance between the occlusal surface and the palatal vault was decreased and the lateral distance appeared enlarged.

- Tongue size as identified by Huynh et al. $(2011)^{20}$ classification by using tongue position and tongue scalloping was as follows:

- Small tongue: tongue edge does not cover lower teeth interesting position. 


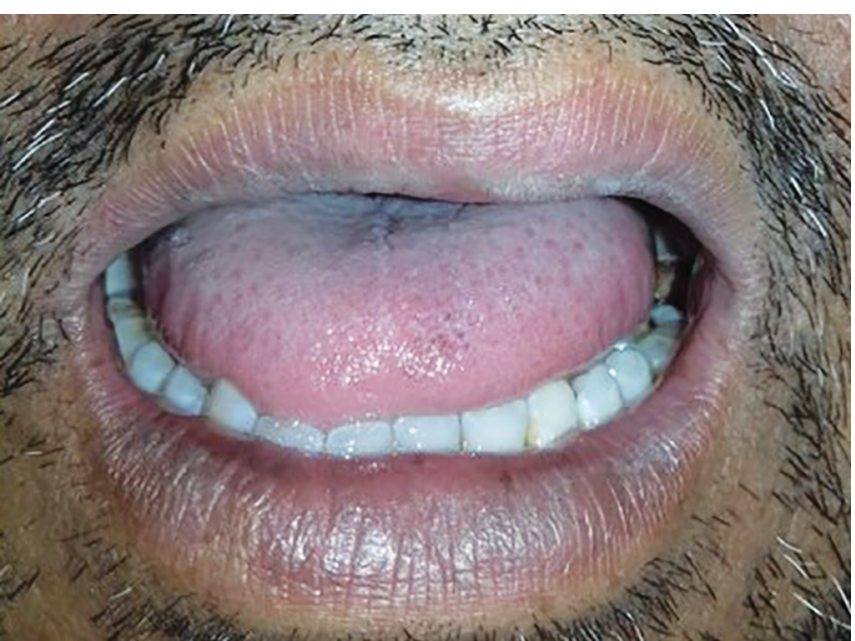

Fig. 1: Intraoral view depicting macroglossia

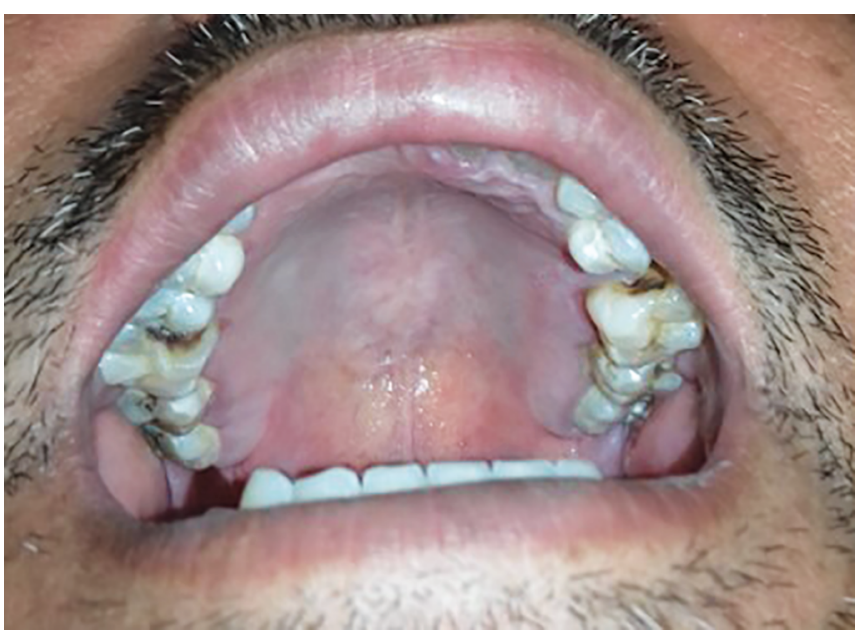

Fig. 2: Intraoral view showing class 4 Mallampati score (hard palate is visible but soft palate and uvula are not visible)

- Normal tongue: tongue edge partially covers lingual cusps of lower teeth.

- Macroglossia: tongue edge covers more than half of lower teeth or scalloped tongue is seen (Fig. 1).

- Modified Mallampati classification ${ }^{21}$ - Participants were asked to protrude their tongues as much as possible in a neutral sitting position and classified according to modified Mallampati classification as follows:

- Class 1: Soft palate and uvula and pillars are completely visible.

- Class 2: Soft palate and uvula are visible.

- Class 3: Soft palate and base of the uvula are visible.

- Class 4: Only hard palate is visible (Fig. 2).

Hard tissue examination includes assessment of the following:

- "Molar relation" as per Angle's Class of Malocclusion (class I, II, or III) along with assessment of deep bite and crowding

- "Periodontitis" was assessed according to the criteria (WHO 1999) $)^{22}$

- Dental attrition/wear facets (present or absent)

- Torus mandibularis (present or absent).
Table 1: Cephalometric parameters analyzed

\begin{tabular}{lcc}
\hline Measure & Abbreviation & \multicolumn{1}{c}{ Abbreviation } \\
\hline $\begin{array}{l}\text { Maxillomandibular } \\
\text { Difference }\end{array}$ & ANB & $\begin{array}{l}\text { Difference between the Angle } \\
\text { between Sella, Nasion and Point }\end{array}$
\end{tabular}

A (SNA) and Angle between Sella, Nasion and Point B (SNB) angles

Maxillary effective Co-A $(\mathrm{mm})$ Distance in millimeter from the length condyle's extreme posterior upper part to point $A$

Mandibular effective length

Co-Gn (mm) Distance in millimeter from the condyle's extreme posterior upper part to point $\mathrm{Gn}$

Maxillary anteroposterior

A-N $(\mathrm{mm}) \quad$ Distance in millimeter from a position Frankfurt's perpendicular plane passing through the Nasion point to point $A$

Mandibular anteroposterior position

Upper pharyngeal space

Pg-N (mm) Distance in millimeter from a Frankfurt's perpendicular plane passing through the Nasion point to point $\mathrm{Pg}$

UFS (mm) Distance in millimeter measured from the soft palate and pharyngeal posterior part throughout a line parallel to plane Go-B passing through the soft palate's most posterior and superior point

Inferior pharyn- IFS (mm) Distance in millimeter from geal space the soft palate and pharyngeal posterior wall throughout the Go-B line

Distance from hyoid bone to

HPM (mm) Distance in millimeter from the hyoid bone's most anterior-superior palate and mandibular plane

\section{Cephalometric Analysis}

High-risk and no-risk (control group) patients were subjected to lateral cephalogram. The lateral cephalogram radiographs were acquired with a sensor-to-source distance of $165 \mathrm{~cm}$ and rigid head fixation on the Soredex Digital Pano D plus Cephalogram Radiography Unit. The technical features of the machine include the current of $5 \mathrm{~mA}$ and the potential difference of $64 \mathrm{kV}$. Patients donned lead aprons and were positioned with Frankfurt horizontal plane (FHP) parallel to the floor, mid sagittal plane perpendicular to the floor, teeth in maximum intercuspation, and lips in rest position. The head position was fixed with ear rods and nasion positioner and an exposure was made.

All cephalograms were processed and imported into Digora software, and manually adjusted for brightness and contrast. The images were imported into Adobe Photoshop 7 and the various parameters were measured. The parameters measured in the lateral cephalogram are discussed in (Table 1, Fig. 3). The obtained values were compared with the control group which consisted of Lateral Cephalograms of normal patients reporting to the radiology department comprising of no risk group.

\section{Statistical Analysis}

Data were entered in Microsoft Excel and analyzed using the program Statistical Package for Social Sciences, version 20.0 (SPSS v.20 Software. For each variable, the Chi-square test was used to 


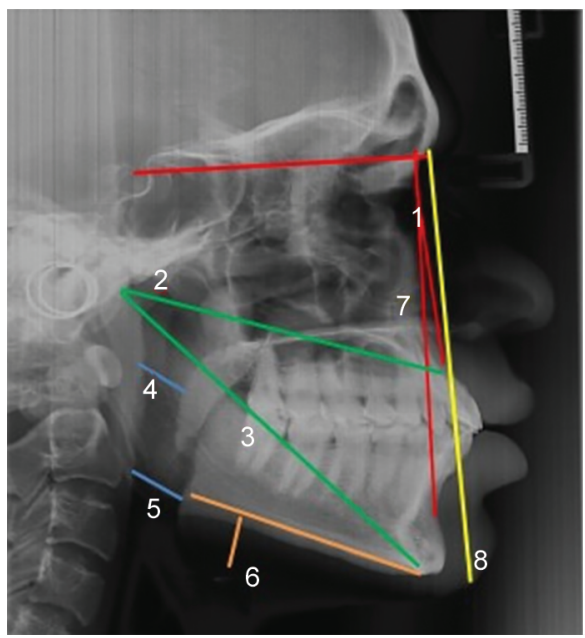

1. Maxillomandibular difference (ANB) angle

2. Maxillary effective length Co-A (mm)

3. Mandibular effectiv length Co-Gn (mm)

4. Upper pharyngeal space UFS (mm)

5. Inferior pharyngeal space IFS ( $\mathrm{mm}$ )

6. Distance from hyoid bone to mandibular plane HPM ( $\mathrm{mm})$

7. Maxillary anteroposterior position A-N (mm)

8. Mandibular anteroposterior position $\mathrm{Pg}-\mathrm{N}(\mathrm{mm})$
Fig. 3: Representation of variables evaluated on lateral cephalogram

assess if there was any significant difference between the groups. Then, using the chi-square test, a multivariate logistic regression was conducted, including those factors in the model that revealed statistically significant differences. For cephalometric analysis, the various parameters were compared between the OSA and control groups, and between men and women. The radiographs were again analyzed after 10 days to assess intraobserver analysis. Kappa measurements were carried out by two different observers. The significance level was set at at $p<0.05$.

\section{Results}

Three hundred patients were screened for the presence of risk of OSA out of which 194 (64.6\%) were men and 106 (35.3\%) were women. One hundred twenty-four (41.3\%) belonged to the high-risk group and 176 (58.6\%) to the low-risk (control) group. Mean age and standard deviation (SD) of the high-risk group is 52.5 and 13.62, respectively. Mean age and SD of the low-risk (control) group is 46.36 and 14.55 , respectively. The parameters measured among the two groups are presented in Table 2. Male gender, BMI, significant neck circumference, presence of TMD, convex facial profile, class 3 and 4 Mallampati score for uvula, large tongue, and deep and medium palatal vault, attrition, wear facets, and tori all exhibited statistically significant differences. Figure 1 depicts a patient with macroglossia. Figure 2 demonstrates patient with class IV Mallampati score, that is, only the hard palate is visible and soft palate and uvula are not visible.

The age-group between 31 and 40 showed a statistically significant correlation for the presence of OSA ( $p=0.0010)$. Prevalence of OSA among men was significantly more than women $(p=0.0220)$. The factors that showed a significant difference were included in the logistic regression model, and the odds ratio for each variable was calculated after controlling for all other variables. The odds ratio for large neck circumference more than 17 inches is 4.6 , for class 4 Mallampati score for uvula is 25.25 , large tongue 7.5 , deep palate 19.80 , and wear facets is 19.80 , according to the multivariate logistic regression (Table 3). Therefore, these factors could have an increased chance of being associated with the risk of developing OSA.

\section{Cephalometric Analysis}

The Mann-Whitney $U$ test was used to compare the variables between men and women participants in the high-risk group and the control group. In case of high-risk group, none of the differences of the variables between men and women are statistically significant. And in case of control group, only the difference of upper pharyngeal space (UFS) and inferior pharyngeal space (IFS) between the men and women is statistically significant $(p<0.05)$.

Table 4 shows the comparison of the variables between male and female participants in the high-risk group and the control group by using Mann-Whitney $U$ test. The mean UFS in high-risk group was $0.72 \pm 0.35$ and in control group $1.32 \pm 0.78$, mean IFS in high-risk group was $1.02 \pm 0.54$ and in control group $1.81 \pm 0.61$. The HPM (distance from hyoid bone to mandibular plane) distance was $2.62 \pm 0.33$ in high-risk group and in control group $1.81 \pm 0.61$. The UFS and IFS measurements in the OSA group were significantly lower than that in the control group, and the MP-H in the OSA highrisk group was significantly greater than in the control group $(p=0.005)$. The maxillary effective length Co-A was greater in the high-risk $5.79 \pm 1.77$ compared to the control group $6.45 \pm 2.01$ $(p=0.005)$. Figures 4 and 5 demonstrate the comparison of airway space and downward displacement of hyoid bone between the high-risk and control group.

\section{Discussion}

Obstructive sleep apnea is associated with several risk factors with prominent clinical implications. Patients with a high risk of developing sleep apnea can be identified through a thorough clinical examination and risk correlational analysis. The existence of oropharyngeal characteristics and radiological findings, which can be used to identify patients at high risk of developing OSA, was investigated in this cross-sectional investigation. In our study, 300 patients were screened using the STOP BANG questionnaire, $41.3 \%$ were within the high-risk group and $58.6 \%$ within the no risk group. The classification of patients into high-risk and no-risk group supported by the STOP BANG questionnaire scores, highlights the importance a radical clinical examination and risk correlational analysis. This study is the first of its kind to assess the presence of dental parameters like TMDs, bruxism with a well-defined criteria, mandibular tori, periodontitis, and attrition in high-risk OSA patients. According to a study the orofacial features such as neck circumference greater than $40 \mathrm{~cm}$, Macroglossia, Class 3 or 4 Mallampati score, and deep palatal vault were important factors in their study predisposing to the 
Table 2: Logistic regression analysis of obstructive sleep apnea (OSA)

\begin{tabular}{|c|c|c|c|c|c|c|c|}
\hline Variables & Factors & No risk & $\%$ & High risk & $\%$ & $\chi^{2}$ & $p$-value \\
\hline \multirow[t]{5}{*}{ Age-groups } & $21-30$ yrs & 29 & 74.36 & 10 & 25.64 & 15.503 & $0.0040^{*}$ \\
\hline & $31-40$ yrs & 41 & 71.93 & 16 & 28.07 & & \\
\hline & $41-50$ yrs & 36 & 62.07 & 22 & 37.93 & & \\
\hline & $51-60$ yrs & 37 & 46.25 & 43 & 53.75 & & \\
\hline & $\geq 61$ yrs & 33 & 50.00 & 33 & 50.00 & & \\
\hline \multirow[t]{2}{*}{ Gender } & Male & 113 & 58.25 & 81 & 41.75 & 0.0401 & 0.8422 \\
\hline & Female & 63 & 59.43 & 43 & 40.57 & & \\
\hline \multirow[t]{2}{*}{ Bruxism } & Absent & 173 & 65.53 & 91 & 34.47 & 42.7401 & $0.0001^{*}$ \\
\hline & Present & 3 & 8.33 & 33 & 91.67 & & \\
\hline \multirow{2}{*}{$\begin{array}{l}\text { Neck circum- } \\
\text { ference }\end{array}$} & $<40 \mathrm{~cm}$ & 151 & 94.38 & 9 & 5.63 & 180.2851 & $0.0001 *$ \\
\hline & $>40 \mathrm{~cm}$ & 25 & 17.86 & 115 & 82.14 & & \\
\hline \multirow[t]{2}{*}{ BMI } & $<35$ & 175 & 75.43 & 57 & 24.57 & 118.6271 & $0.0001^{*}$ \\
\hline & $>35$ & 1 & 1.47 & 67 & 98.53 & & \\
\hline \multirow[t]{3}{*}{ Profile } & $\mathrm{CC}$ & 4 & 80.00 & 1 & 20.00 & 0.9541 & 0.6212 \\
\hline & convex & 137 & 58.30 & 98 & 41.70 & & \\
\hline & ST & 35 & 58.33 & 25 & 41.67 & & \\
\hline \multirow[t]{2}{*}{ TMD } & Absent & 173 & 64.31 & 96 & 35.69 & 34.2172 & $0.0001^{*}$ \\
\hline & Present & 3 & 9.68 & 28 & 90.32 & & \\
\hline \multirow[t]{2}{*}{ Macroglossia } & Absent & 160 & 97.56 & 4 & 2.44 & 225.6871 & $.0001^{*}$ \\
\hline & Present & 16 & 11.76 & 120 & 88.24 & & \\
\hline \multirow[t]{3}{*}{ Palate } & $\mathrm{D}$ & 5 & 4.81 & 99 & 95.19 & 194.5580 & $0.0001^{*}$ \\
\hline & M & 114 & 82.61 & 24 & 17.39 & & 0.267 \\
\hline & $S$ & 57 & 98.28 & 1 & 1.72 & & \\
\hline \multirow[t]{4}{*}{ Mal score } & 1 & 46 & 97.87 & 1 & 2.13 & 252.117 & 0.135 \\
\hline & 2 & 118 & 99.16 & 1 & 0.84 & & $0.0200^{*}$ \\
\hline & 3 & 8 & 27.59 & 21 & 72.41 & & $0.0001^{*}$ \\
\hline & 4 & 4 & 3.81 & 101 & 96.19 & & \\
\hline \multirow[t]{2}{*}{ Periodontitis } & Absent & 103 & 88.79 & 13 & 11.21 & 70.7890 & $0.0050^{*}$ \\
\hline & Present & 73 & 39.67 & 111 & 60.33 & & \\
\hline \multirow[t]{2}{*}{ Attrition } & Absent & 151 & 94.97 & 8 & 5.03 & 183.8512 & $0.0001^{*}$ \\
\hline & Present & 25 & 17.73 & 116 & 82.27 & & \\
\hline \multirow[t]{2}{*}{ Wear facets } & Absent & 172 & 86.87 & 26 & 13.13 & 191.009 & $0.0001^{*}$ \\
\hline & Present & 4 & 3.92 & 98 & 96.08 & & \\
\hline \multirow[t]{2}{*}{ Tori } & Absent & 176 & 67.43 & 85 & 32.57 & 63.626 & \\
\hline & Present & 0 & 0.00 & 39 & 100.00 & & \\
\hline \multirow[t]{2}{*}{ Mal occlusion } & I & 174 & 59.79 & 117 & 40.21 & 5.0821 & $0.0240^{*}$ \\
\hline & II & 2 & 22.22 & 7 & 77.78 & & \\
\hline \multirow[t]{2}{*}{ Crowding } & Absent & 175 & 59.52 & 119 & 40.48 & 4.454 & $0.0350^{*}$ \\
\hline & Present & 1 & 16.67 & 5 & 83.33 & & \\
\hline \multirow[t]{3}{*}{ Deep bite } & Absent & 173 & 58.84 & 121 & 41.16 & 0.0001 & 1.0000 \\
\hline & Present & 3 & 50.00 & 3 & 50.00 & & \\
\hline & Total & 176 & 58.67 & 124 & 41.33 & & \\
\hline
\end{tabular}

BMI, body mass index; OSA, obstructive sleep apnea; TMD, temporomandibular disorder

*Significance at $p<0.05, \chi^{2}=$ Chi-squared test value

development of high risk of OSA. ${ }^{14}$ Our study screened patients for OSA reporting to the dental outpatient department (OPD).

Our study identified a high male predominance in the high-risk group (64.6\%) and is substantiated in the preliminary study by Block et al. ${ }^{23}$ and Kale et al. ${ }^{14}$ A statistically significant male predominance was noted. High prevalence of obesity is another significant factor to assess the severity of OSA. The high-risk group had 67 times more risk of developing OSA in the present study. The BMI is the product of a calculation related to an individual's weight and height, indicating an overweight condition. This was substantiated within the present study and emphasized in the other studies. ${ }^{12,14}$

- Approximately $46.67 \%$ of the high-risk groups had a neck circumference larger than $40 \mathrm{~cm}$. Excess fat accumulation around the neck constricts the pharyngeal region causing upper airway collapse. Modified Mallampati class 3 and 4 score, are high risk 
Table 3: Odds ratio of variables included in logistic regression model

\begin{tabular}{lllll}
\hline Factors & OR & $\begin{array}{l}95 \% \mathrm{Cl} \\
\text { Upper }\end{array}$ & $\begin{array}{l}\text { OR } \\
\text { Lower }\end{array}$ & p value \\
\hline Age-groups & 0.39 & 0.22 & 0.70 & $0.0010^{*}$ \\
31-41 & & & & \\
Males & 0.72 & 0.54 & 0.95 & $0.0220^{*}$ \\
Bruxism & 11.00 & 3.37 & 35.87 & $0.0001^{*}$ \\
Neck circumference $>17$ & 4.60 & 2.99 & 7.09 & $0.0001^{*}$ \\
BMl>35 & 67.00 & 9.30 & 482.62 & $0.0001^{*}$ \\
Convex Profile & 0.72 & 0.55 & 0.93 & $0.0110^{*}$ \\
TMD & 9.33 & 2.84 & 30.70 & $0.0001^{*}$ \\
Macroglossia & 7.50 & 4.45 & 12.64 & $0.0001^{*}$ \\
Deep Palate & 19.80 & 8.06 & 48.62 & $0.0001^{*}$ \\
Mal score 3 & 2.63 & 1.16 & 5.93 & $0.0200^{*}$ \\
Mal score 4 & 25.25 & 9.30 & 68.58 & $0.0001^{*}$ \\
Periodontitis & 1.52 & 1.13 & 2.04 & $0.0050^{*}$ \\
Attrition & 4.64 & 3.01 & 7.15 & $0.0001^{*}$ \\
Wear facets & 24.50 & 9.02 & 66.58 & $0.0001^{*}$ \\
\hline
\end{tabular}

$\mathrm{OR}$, Odds ratio; $\mathrm{Cl}$, Confidence Interval factors for OSA and signify a narrow oropharyngeal airway. While sleeping the tongue falls back posteriorly and the constricted pharyngeal space causes airway distress. ${ }^{24,25}$ The risk of OSA in subjects with Mallampati class 4 was 25 times higher than that in those with Mallampati class 3 and 2 in the present study. Previous studies have also shown that a narrow oropharyngeal space increases the risk of OSA. ${ }^{12,14,26}$ The prevalence of macroglossia was found to be 7.5 times more common in the high-risk group compared to the low-risk group. The muscle tonus decreases during sleep and due to its large volume as seen in macroglossia, the tongue collapses and masks the posterior area including tonsillar pillars and uvula causing respiratory distress. ${ }^{26}$ Ruangsri et al. ${ }^{27}$ and Weiss et al. ${ }^{28}$ observed similar results.

OSA has been linked to periodontal disease and has been substantiated by several cross-sectional studies ${ }^{29-32}$ with an OR between 1.75 and 1.84 . In the present study, periodontitis was seen in 111 patients within the high-risk group with OR of 1.52 . A higher prevalence of periodontitis among patients with OSA, was demonstrated by Gunaratnam et al. ${ }^{29}$ signifying a probable association between OSA and periodontitis. Management of periodontitis shows desirable effects such as decreased systemic inflammation, metabolic control of glycemia, and improved

Table 4: Comparison of the cephalometric parameters between the high-risk and control groups

\begin{tabular}{|c|c|c|c|c|c|c|c|c|c|}
\hline \multirow[b]{2}{*}{ Parameters } & \multicolumn{4}{|c|}{ High risk } & \multicolumn{4}{|c|}{ No risk/Control } & \multirow[b]{2}{*}{$p$ value } \\
\hline & Mean & $S D$ & Lower & Upper & Mean & $S D$ & Lower & Upper & \\
\hline Age & 52.60 & 13.57 & 22.00 & 81.00 & 29.64 & 7.41 & 16.00 & 50.00 & 0.975 \\
\hline ANB & 6.13 & 1.68 & 1.30 & 13.00 & 6.33 & 1.80 & 2.40 & 10.50 & 0.444 \\
\hline Co-A & 5.79 & 1.77 & 2.40 & 10.50 & 6.45 & 2.01 & 2.60 & 11.30 & $0.014^{*}$ \\
\hline Co-Gn & 7.66 & 2.19 & 2.60 & 11.80 & 7.66 & 2.12 & 2.60 & 11.80 & 0.967 \\
\hline$A-N$ & 2.84 & .46 & 2.15 & 4.32 & 2.81 & 0.43 & 2.15 & 4.32 & 0.729 \\
\hline $\mathrm{Pg}-\mathrm{N}$ & 7.47 & 1.62 & 4.63 & 10.35 & 7.33 & 1.67 & 4.63 & 10.35 & 0.533 \\
\hline UFS & .72 & .35 & .06 & 1.98 & 1.32 & 0.78 & 0.06 & 2.92 & $0.000^{*}$ \\
\hline IFS & 1.02 & .54 & .06 & 2.75 & 1.81 & 0.61 & 0.33 & 2.95 & $0.000^{*}$ \\
\hline HPM & 2.62 & .33 & 1.75 & 4.32 & 1.06 & 0.64 & 0.05 & 2.90 & $0.000^{*}$ \\
\hline
\end{tabular}

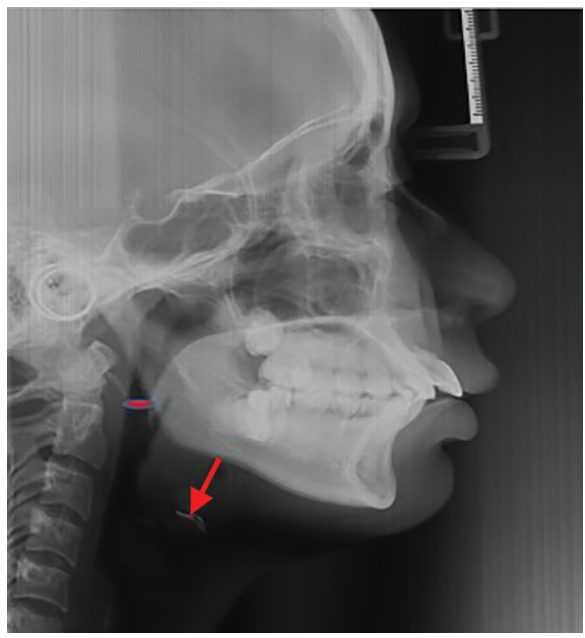

Fig. 4: Lateral cephalogram of high-risk patients showing decreased airway space and increased MP-H distance

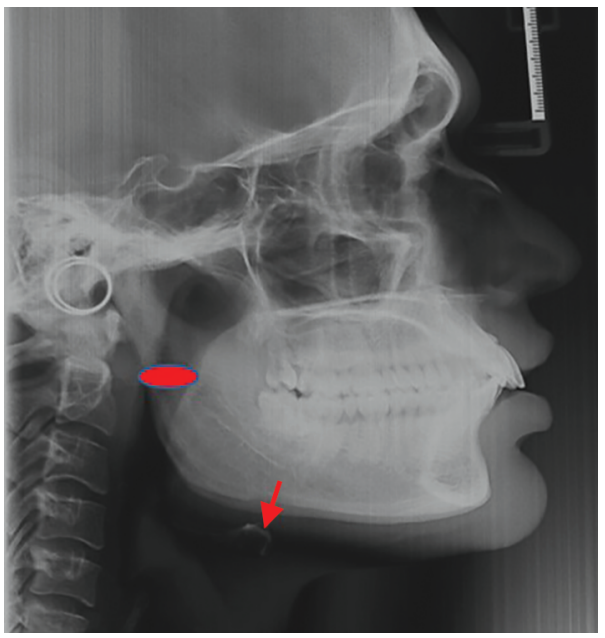

Fig. 5: Lateral cephalogram of control subject showing increased airway space and decreased MP-H distance 
parameters of vascular health. ${ }^{33,34}$ Diagnosis and management of periodontitis must be included in the treatment protocol and maybe a novel approach to improve OSA.

The present study showed a prevalence of $22.58 \%$ for TMDs (myofascial pain) in the high-risk group which was statistically significant. The TMJ pain experienced over time is through the effect of central sensitization and pain amplification in decreasing function in pain inhibitory systems, for example, via baroreceptor pathways. ${ }^{35}$ The overactivity of the sympathetic nervous system detected in OSA could trigger the occurrence of TMD. Patients with genetic susceptibility to heightened action of catecholamines are at risk of developing TMD. ${ }^{36}$

Attrition and temporomandibular problems have been proposed by several authors ${ }^{37,38}$ as outcomes of OSA rather than risk factors. The current study found a significant odds ratio of patients with attrition and TMD in the high-risk OSA group compared to the no-risk OSA group. When the tongue collapses posteriorly, reducing airway space, the body may activate an inherent defence mechanism that causes the mandible to move forward unknowingly to create space for air in the upper airway region, causing tooth attrition. This action caused by the forward movement of the mandible repeatedly leads to excessive strain on the TMJ leading to TMDs. ${ }^{39}$ The present study shows the presence of wear facets and attrition in a statistically significant number of high-risk OSA patients. Consistent results were seen in a study to assess the frequency of OSA in patients with dental wear (attrition). ${ }^{40} \mathrm{~A}$ high correlation was seen between $\mathrm{AHI}$ severity and tooth wear severity. The authors concluded that tooth wear could be used as a diagnostic tool to identify patients at risk of having OSA.

In the present study, patients demonstrated an increased prevalence of Angle's class I malocclusion than Angle's class 2 malocclusion among high-risk OSA group as compared to the no-risk control group. The findings were similar to those of Al-Madani et al. ${ }^{41}$ and Triplett et al. ${ }^{42}$ who found Angle's class 2 malocclusion to be a risk factor for OSA but did not find it to be a risk factor for OSA. Banabilh et al. ${ }^{43}$ identified some discrepancies in their findings. No significant association of dental crowding, deep bite, and facial profile was seen within the high-risk group of patients with OSA. An increased association of deep bite was seen in the present study with OR of 19.20 in the high-risk group. It's in concordance with the study carried out by Kale et al. ${ }^{14}$ but in contrast to the study conducted by Ruangsri et al. ${ }^{27}$

A novel, notable finding in the present study is the presence of mandibular tori in high-risk patients $(39 / 85 ; p=0.00001$. Large mandibular tori can predispose patients to OSA. Tori are large bony masses, which dwell in the tongue space, causing tongue collapse and upper airway obstruction. ${ }^{44}$ This airway restriction could manifest as OSA, as measured by sleep devices. A case of large mandibular tori causing OSA was reported which after surgical excision demonstrated a reduction in the $\mathrm{AHI} .{ }^{45}$

A high prevalence of probable bruxism [26.12\% (33/124) $p=0.0001]$ is seen in the present study. The results are consistent with a study by Phillips et al., ${ }^{46}$ which demonstrated a positive correlation between episodes of tooth clenching and apnea. According to previous research studies, 35\% of tooth grinders present with snoring and approximately $30 \%$ of OSA reported of bruxism. ${ }^{47}$ A pilot study by Winck et al. ${ }^{48}$ showed the presence of bruxism in 9 out of 11 OSA patients. A statistically significant positive correlation was found between tooth grinding episodes and OSA $(R=0.755)$.
Lateral cephalograms of the high-risk and low-risk (control group) patients provided significant results. Cephalometric analysis demonstrated decrease in the upper and inferior pharyngeal airway spaces (UFS and IFS) in the high-risk group and the MP-H in the OSA high-risk group was significantly greater in the control group $(p<0.05)$. Literature search revealed several studies reporting smaller airway diameters in patients with OSA. ${ }^{49}$ According to Szymanska et al. ${ }^{50}$ the width of the upper airway was decreased than the typical values standardized by Mc-Namara on lateral cephalograms in patients with OSA. Martin et al. ${ }^{51}$ corelated the increased episodes of apnea or hypoapnea with decreased upper airway diameter. It was also deciphered that the values reduced drastically when the patients were observed in lying down position.

The distance between the hyoid and mandible was significantly increased in the OSA group $(p<0.05)$. this finding indicated that the hyoid bone was positioned more downward in the OSA group. According to Arya et al. ${ }^{52}$ this downward position of the hyoid with a lower tongue posture may increase the mandibular load due to the need of additional energy to elevate the tongue; this, in turn, may aggravate apnea by leading to the open-mouth posture during sleep.

The downward positioning of hyoid may be a poor prognostic indicator for the successful use of mandibular advancement splints which are utilized in the treatment of OSA. ${ }^{53}$ The MP-H distance was $4.14 \mathrm{~mm}$ larger in OSA patients than in controls in a meta-analysis by Armalaite et al. ${ }^{54}$ They came to the conclusion that greater MP-H readings might be used to distinguish between healthy people and OSA patients.

\section{Limitation and Future Directions}

A major limitation of the study is the absence of gold standard PSG, in identifying OSA. High cost and decreased feasibility are the major reasons to abstain from performing PSG. Polysomnography is an effective test to diagnose OSA, but the origin of airway obstructions that produce OSA cannot be identified by PSG. Lateral cephalometric radiography may be a useful gizmo to gauge the airway obstructions in these individuals but cannot predict the transverse diameter and airway volume. Therefore, the cephalograms remain a facultative preliminary tool for upper airway evaluation, thanks to low cost and convenience, despite the recognition of 3D images like cone beam computerized tomography (CBCT). Cone beam computerized tomography helps in assessing the transverse diameter and airway volume but is associated with increased radiation dose and cost as compared to cephalograms. Cephalometry combined with clinical factors, physical examination, and nocturnal was useful in the screening of OSA, according to Lavanya et al. ${ }^{55}$ and Julià-Serdà et al., ${ }^{56}$ and the combination of those approaches can greatly minimize the quantity of polysomnography examinations undertaken by patients. Future studies should focus on screening patients for high-risk OSA through questionnaires and oropharyngeal examination. PSG and advanced imaging modalities can be advised depending on the severity of OSA.

\section{Conclusion}

The current study highlights the significance of clinical signs and symptoms, as well as the STOP-BANG questionnaire, in detecting OSA risk factors. Increasing age, male gender, BMI, large neck circumference, class 3 and 4 Mallampati score for uvula, macroglossia, large mandibular tori, and radiological parameters 
such as decreased upper and lower pharyngeal space with downward displacement of hyoid bone are risk factors for OSA. Presence of TMD, attrition, and bruxism are consequences and convex facial profile and periodontitis are associated factors for OSA and were corroborated in the present study.

\section{Clinical Significance}

Dental sleep medicine is an upcoming branch with diversified treatment modalities. We as dentists are in constant exposure to the oral cavity and can assess the different oropharyngeal parameters associated with OSA. This study throws light on the imperative role of orofacial features in OSA patients. The oral and radiographic findings can be used as preliminary tools for early screening of patients with high risk of OSA. These patients can be further referred for confirmatory tests like PSG and 3D imaging. Since OSA has been related to the development of medical disorders, it is critical to educate patients about sleep problems and their repercussions. It is imperative to enquire about the patient's sleep history, evaluate them with accessible validated questionnaires, and direct them to a sleep physician if necessary, supporting interdisciplinary therapy.

\section{Author Contributions}

The manuscript has been read and approved by all the authors, the requirements for authorship has been stated below and each author believes that the manuscript represents honest work.

\begin{tabular}{|c|c|c|c|c|c|c|}
\hline S. No. & Work & & Contributc & & & \\
\hline & & 1 & 2 & 3 & 4 & 5 \\
\hline 1. & Concept and design & Dr Deepa & & & & \\
\hline 2. & $\begin{array}{l}\text { Definition of } \\
\text { intellectual content }\end{array}$ & Dr Deepa & & & & \\
\hline 3. & Literature research & Dr Deepa & Dr Manjiri & & & \\
\hline 4. & Clinical studies & Dr Deepa & Dr Manjiri & & & \\
\hline 5. & $\begin{array}{l}\text { Manuscript } \\
\text { preparation }\end{array}$ & Dr Deepa & & & & \\
\hline 6. & $\begin{array}{l}\text { Manuscript editing } \\
\text { and manuscript } \\
\text { review }\end{array}$ & Dr Deepa & Dr Manjiri & & & \\
\hline
\end{tabular}

\section{References}

1. Huynh NT, Emami E, Helman Jl, et al. Interactions between sleep disorders and oral diseases. Oral Dis 2014;20(3):236-245. DOI: 10.1111/odi.12152. Epub 2013 Jul 2.

2. Benjafield AV, Ayas NT, Eastwood PR, et al. Estimation of the global prevalence and burden of obstructive sleep apnoea: a literature based analysis. Lancet Respir Med 2019;7(8):687-698. DOI: 10.1016/S2213-2600(19)30198-5

3. Heinzer R, Vat S, Marques-Vidal P, et al. Prevalence of sleep-disordered breathing in the general population: the Hypno Laus study. Lancet Respir Med 2015; 3:310-318. DOI: 10.1016/S2213-2600(15)00043-0

4. Peppard PE, Young T, Barnet JH, et al. Increased prevalence of sleep-disordered breathing in adults. Am J Epidemiol 2013; 177:1006-1014. DOI: 10.1093/aje/kws342

5. Hasan A, Uzma N, Swamy TL, et al. Correlation of clinical profiles with obstructive sleep apnea and metabolic syndrome. Sleep Breath 2012; 16:111-116. DOI: 10.1007/s11325-010-0463-z

6. Gianoni-Capenakas S, Gomes AC, Mayoral P, et al. Sleep-disordered breathing: the dentists' role - a systematic review. J Dent Sleep Med 2020;7(1):1-15. DOI: 10.15331/jdsm
7. Kapur VK, Auckley DH, Chowdhuri S, et al. Clinical practice guideline for diagnostic testing for adult obstructive sleep apnea: an American Academy of Sleep Medicine clinical practice guideline. J Clin Sleep Med 2017;13(3):479-504. DOI: 10.5664/jcsm.6506

8. Flemons WW, Douglas NJ, Kuna ST, et al. Access to diagnosis and treatment of patients with suspected sleep apnea. Am J Respir Crit Care Med 2004;169(6):668-672. DOI: 10.1164/rccm.200308-1124PP

9. Luo J, Huang R, Zhong X, et al. STOP-Bang questionnaire is superior to Epworth sleepiness scales, Berlin questionnaire, and STOP questionnaire in screening obstructive sleep apnea hypopnea syndrome patients. Chin Med J 2014;127(17):3065-3070.

10. Chung F, Yegneswaran B, Liao P, et al. STOP questionnaire: a tool to screen patients for obstructive sleep apnea. Anesthesiology 2008;108(5):812-821. DOI: 10.1097/ALN.0b013e31816d83e4

11. Senaratna CV, Perret JL, Lodge CJ, et al. Prevalence of obstructive sleep apnea in the general population: a systematic review. Sleep Med Rev 2017; 34:70-81. DOI: 10.1016/j.smrv.2016.07.002

12. Schellenberg JB, Maislin G, Schwab RJ. Physical findings and the risk for obstructive sleep apnea. The importance of oropharyngeal structures. Am J Respir Crit Care Med 2000;162:740-748. DOI: 10.1164/ajrccm.162.2.9908123

13. Sharma SK, Ahluwalia G. Epidemiology of adult obstructive sleep apnea syndrome in India. Indian J Med Res 2010;131:171-175.

14. Kale SS, Kakodkar P, Shetiya SH. Assessment of oral findings of dental patients who screen high and no risk for obstructive sleep apnea (OSA) reporting to a dental college - a cross sectional study. Sleep Sci 2018;11(2):112-117. DOI: 10.5935/1984-0063.20180021

15. Chung F, Abdullah HR, Liao P. STOP-Bang Questionnaire: a practical approach to screen for obstructive sleep apnea. Chest 2016;149(3):631-638.

16. WHO. Physical status: the use and interpretation of anthropometry. Report of a WHO Expert Consultation. WHO Technical Report Series Number 854. Geneva: World Health Organization;1995.

17. Oh J, Han JJ, Ryu SY, et al. Clinical and cephalometric analysis of facial soft tissue. J Craniofac Surg 2017;28(5):e431-e438. DOI: $10.1097 /$ SCS.0000000000003614

18. Schiffman E, Ohrbach R, Truelove E, et al. Diagnostic criteria for temporomandibular disorders (DC/TMD) for clinical and research applications: recommendations of the international RDC/TMD Consortium Network and Orofacial Pain Special Interest Group. J Orofacial Pain Headache 2014;28(1):6-27. DOI: 10.11607/jop.1151

19. American Academy of Sleep Medicine (AASM). The International Classification of Sleep Disorders Revised: Diagnostic and Coding Manual (ICSD), 2nd edn. Westchester, IL: American Academy of Sleep Medicine; 2005.

20. Huynh NT, Morton PD, Rompré PH, et al. Associations between sleep-disordered breathing symptoms and facial and dental morphometry, assessed with screening examinations. Am J Orthod Dentofacial Orthop 2011;140(6);762-770. DOI: 10.1016/j. ajodo.2011.03.023

21. Samsoon GL, Young JR. Difficult tracheal intubation: a retrospective study. Anaesthesia 1987; 42:487. DOI: 10.1111/j.1365-2044.1987. tb04039.x

22. International Workshop for a Classification of Periodontal Diseases and Conditions. Papers. Oak Brook, Illinois, October 30-November 2, 1999. Ann Periodontol 4:1-112.

23. Block AJ, Boysen PG, Wynne JW, et al. Sleep apnea, hypopnea and oxygen desaturation in normal subjects. A strong male predominance. N Engl J Med 1979;300(10):513-517. DOI: 10.1056/ NEJM197903083001001

24. Whyte A, Gibson D. Adult obstructive sleep apnea: pathogenesis, importance, diagnosis and imaging. J Med Imaging Radiat Oncol 2020; 64(1):52-66. DOI: 10.1111/1754-9485.12978

25. Rodrigues MM, Dibbern RS, Goulart CW. Nasal obstruction and high Mallampati score as risk factors for obstructive sleep apnea. Braz J Otorhinolaryngol 2010;76(5):596-599.

26. lida-Kondo C, Yoshino N, Kurabayashi T, et al. Comparison of tongue volume/oral cavity volume ratio between obstructive sleep apnea 
syndrome patients and normal adults using magnetic resonance imaging J MedDent Sci 2006;53(2):119-126.

27. Ruangsri S, Jorns TP, Puasiri S, et al. Which oropharyngeal factors are significant risk factors for obstructive sleep apnea? An age matched study and dentist perspectives. Nat Sci Sleep 2016;8:215-219. DOI: $10.2147 /$ NSS.S96450

28. Weiss TM, Atanasov S, Calhoun KH. The association of tongue scalloping with obstructive sleep apnea and related sleep pathology. Otolaryngol Head Neck Surg 2005;133(6):966-971. DOI: 10.1016/j. otohns.2005.07.018

29. Gunaratnam K, Taylor B, Curtis B, et al. Obstructive sleep apnea and periodontitis: a novel association? Sleep Breath 2009; 13:233-239. DOI: 10.1007/s11325-008-0244-0

30. Keller JJ, Wu CS, Chen YH, et al. Association between obstructive sleep apnea and chronic periodontitis: a population-based study. J Clin Periodontol 2013; 40:111-117. DOI: 10.1111/jcpe.12036

31. Seo WH, Cho ER, Thomas RJ, et al. The association between periodontitis and obstructive sleep apnea: a preliminary study. J Periodontal Res 2013; 48:500-506.DOI: 10.1111/jre.12032

32. Ahmad NE, Sanders AE, Sheats R, et al. Obstructive sleep apnea in association with periodontitis: a case-control study. J Dent Hyg 2013;87: 188-199.

33. Blum A, Front E, Peleg A. Periodontal care may improve systemic inflammation. Clin Invest Med 2007;30:E114-E117. DOI: 10.25011/cim. v30i3.1079

34. Vidal F, Figueredo CM, Cordovil I, et al. Periodontal therapy reduces plasma levels of interleukin- 6, C-reactive protein, and fibrinogen in patients with severe periodontitis and refractory arterial hypertension. J Periodontol 2009; 80:786-791. DOI: 10.1902/ jop.2009.080471

35. Smith MT, Wickwire EM, Grace EG, et al. Sleep disorders and their association with laboratory pain sensitivity in temporomandibular joint disorder. Sleep 2009; 32:779-790. DOI: 10.1093/sleep/32.6.779

36. Diatchenko L, Slade GD, Nackley AG, et al. Genetic basis for individual variations in pain perception and the development of a chronic pain condition. Hum Mol Genet 2005; 14:135-143. DOI: 10.1093/hmg/ddi013

37. Sanders AE, Essick GK, Fillingim R, et al. Sleep apnea symptoms and risk of temporomandibular disorder: OPPERA cohort. J Dent Res 2013;92(7):70S-77S. DOI: 10.1177/0022034513488140

38. Cunali PA, Almeida FR, Santos CD, et al. Prevalence of temporomandibular disorders in obstructive sleep apnea patients referred for oral appliance therapy J Orofac Pain 2009; 23(4):339-344.

39. Balasubramaniam R, Klasser GD, Cistulli PA, et al. The link between sleep bruxism, sleep disordered breathing and temporomandibular disorders: an evidence-based review. J Dent Sleep Med 2014;1(1):27-37.

40. Durán-Cantolla J, Alkhraisat MH, Martínez-Null C, et al. Frequency of obstructive sleep apnea syndrome in dental patients with tooth wear. J Clin Sleep Med 2015;11(4):445-450. DOI: 10.5664/jcsm.4602

41. Al-Madani GH, Banabilh SM, El-Sakhawy MM. Prevalence of snoring and facial profile type, malocclusion class and dental arch morphology among snorer and nonsnorer university population. J Orthod Sci 2014;4(4):108-112. DOI: 10.4103/2278-0203.173424
42. Triplett WW, Lund BA, Westbrook PR, et al. Obstructive sleep apnea syndrome in patients with class II malocclusion. Mayo Clin Proc 1989;64(6):644-652. DOI: 10.1016/s0025-6196(12)65342-7

43. Banabilh SM, Samsudin AR, Suzina AH, et al. Facial profile shape, malocclusion and palatal morphology in Malay obstructive sleep apnea patients. Angle Orthod 2010;80(1):37-42. DOI: 10.2319/011509-26.1

44. Palm E, Franklin KA, Marklund M. Mandibular tori size is related to Obstructive sleep apnea and treatment success with an oral appliance. Sleep Breath 2014; 18:431-438.DOI: 10.1007/s11325-013-0905-5

45. Singh GD, Cress SE, McGuire MK et al. Case report: effect of mandibular tori removal on obstructive sleep apnea parameters. Dialogue 2012;1:22-24.

46. Phillips BA, Okeson J, Paesani D, et al. Effect of sleep position on sleep apnea and parafunctional activity. Chest 1986; 90:424-429. DOI: 10.1378/chest.90.3.424

47. Lavigne GJ, Khoury S, Abe S, et al. Bruxism physiology and pathology: an overview for clinicians. J Oral Rehabil 2008; 35:476-494. DOI: 10.1111/j.1365-2842.2008.01881.x

48. Winck $M$, Drummond $M$, Vianac $P$, et al. Sleep bruxism associated with obstructive sleep apnea syndrome-a pilot study using a new portable device. Rev Port Pneumol 2017;23(1):22-26. DOI: 10.1016/j. rppnen.2016.07.001

49. Gungor AY, Turkkahraman $\mathrm{H}$, Yilmaz HH, et al. Cephalometric comparison of obstructive sleep apnea patients and healthy controls. Eur J Dent 2013;7(1):48-54.

50. Szymanska J, Dobrowolska-Zarzycka M. The influence of upper airways diameter on the intensity of obstructive sleep apnea. Ann Agric Environ Med 2014;21:217-220. DOI: 10.5604/12321966.1095371

51. Martin SE, Mathur R, Marshall I, et al. The effect of age, sex, obesity and posture on upper airway size. Eur Respir J 1997;10:2087-2090. DOI: 10.1183/09031936.97.10092087

52. Arya D, Tripathi A, Singh SV, et al. A pilot study to evaluate posttreatment cephalometric changes in subjects with OSA.JProsthet Dent 2010;103:170-177. DOI: 10.1016/S0022-3913(10)60024-8

53. Mayer G, Meier-Ewert K. Cephalometric predictors for orthopaedic mandibular advancement in obstructive sleep apnea. Eur J Orthod 1995;17:35-43. DOI: 10.1093/ejo/17.1.35

54. Armalaite J, Lopatiene K. Lateral teleradiography of the head as a diagnostic tool used to predict obstructive sleep apnea. Dentomaxillofac Radiol 2016;45:20150085. DOI: 10.1259/dmfr.20150085

55. Lavanya R, Gandhi Babu DB, Chavva S, et al. The role of oral physicians in predicting the risk of obstructive sleep apnea: a case-control study. Imaging Sci Dent 2016;46(3)167-171. DOI: 10.5624/isd.2016.46.3.167

56. Julià-Serdà G, Pérez-Peñate G, Saavedra-Santana P, et al. Usefulness of cephalometry in sparing polysomnography of patients with suspected obstructive sleep apnea. Sleep Breath 2006; 10:181-187. DOI: $10.1007 / \mathrm{s} 11325-006-0073-y$ 